\title{
Building and characterizing regional and global emission inventories of toxic pollutants
}

Cucurachi, S.; Sala, S.; Laurent, A.; Heijungs, R.

\section{Citation}

Cucurachi, S., Sala, S., Laurent, A., \& Heijungs, R. (2014). Building and characterizing regional and global emission inventories of toxic pollutants. Environmental Science \& Technology, 48(10), 5674-5682. doi:10.1021/es405798x

Version: $\quad$ Publisher's Version

License: $\quad$ Licensed under Article 25fa Copyright Act/Law (Amendment Taverne)

Downloaded from: https://hdl.handle.net/1887/3217432

Note: To cite this publication please use the final published version (if applicable). 


\title{
Building and Characterizing Regional and Global Emission Inventories of Toxic Pollutants
}

\author{
Stefano Cucurachi, ${ }^{*}{ }^{\dagger}$ Serenella Sala, ${ }^{\ddagger}$ Alexis Laurent, ${ }^{\S}$ and Reinout Heijungs ${ }^{\dagger, \perp}$ \\ ${ }^{\dagger}$ Institute of Environmental Sciences (CML), Leiden University, P.O. Box 9518, 2300 RA Leiden, The Netherlands \\ ${ }^{\ddagger}$ Sustainability Assessment Unit, European Commission, DG Joint Research Centre, Institute for Environment and Sustainability, Via \\ Enrico Fermi, 2749, 21027 Ispra Varese, Italy \\ ${ }^{\S}$ Division for Quantitative Sustainability Assessment (QSA), Department of Management Engineering, Technical University of \\ Denmark (DTU), Anker Engelunds Vej 1, 2800 Kongens Lyngby, Denmark \\ ${ }^{\perp}$ Department of Econometrics and Operations Research, VU University Amsterdam, De Boelelaan 1105, 1081 HV Amsterdam, The \\ Netherlands
}

\section{Supporting Information}

\begin{abstract}
To define consistent strategies for managing the environmental sustainability of chemicals, it is important to quantify the magnitude of their emissions and their associated impacts. Not all countries monitor and report emissions related to their activities. This is particularly the case for chemical emissions, whose toxic impacts on human health and ecosystems cannot be readily determined because of gaps in the available data. Emission data that can be retrieved from publicly available databases are typically restricted to a limited number of toxic substances, for a few countries, or for aggregated regions. Extrapolation strategies are thus needed to fill in those data gaps and to move from the consideration of single countries or regions to the world scale. Little is known about how effective these strategies are in extrapolating emissions. With the use of emission data available in public databases in the world, the current work explores different opportunities to compile representative inventories of toxic emissions. In this study, we build global and European emission inventories using three extrapolation proxies, namely the gross domestic product, the emissions of carbon dioxide, and the emissions of mercury. The three proxies are compared and their efficacies are tested statistically to identify the best performer for specific classes of substances. The potential impacts associated with the emissions in the European and global inventory are further tested by using an impact system adopted for the comparative assessment of chemicals in the field of life cycle assessment.

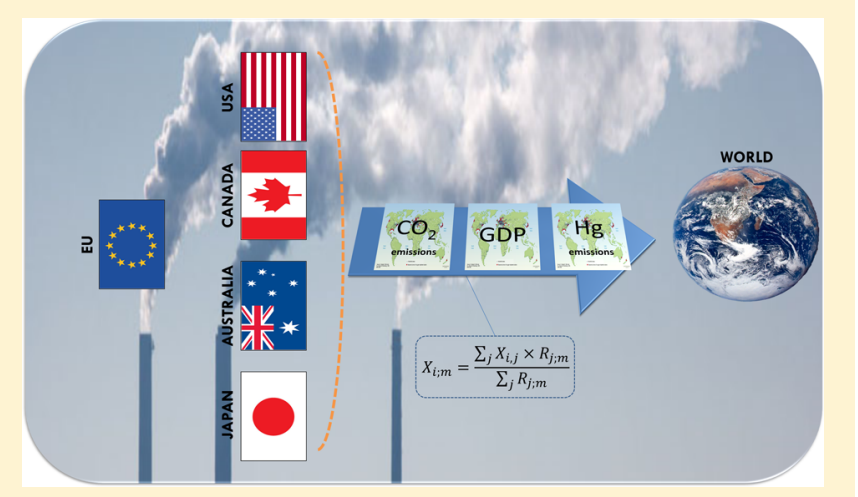

\section{INTRODUCTION}

In decision- and policy-making for environmental sustainability, one key aspect is to know the quantity of a substance emitted and its associated toxicological impacts on ecosystems, health, and human health. This data can be used for establishing regulations for a better management of chemicals in processes and products (e.g., limiting or banning the use of toxicants). At the country or continental levels, emission data can be required to assess large-scale systems, for example, in the context of nation footprinting ${ }^{1-3}$ and other ongoing footprinting developments as in, for example, those by Sala et al. ${ }^{6}$ Life cycle assessment (LCA), which is a decision-support tool that allows for the quantification of potential impacts from a system, ${ }^{4,5}$ can also require large-scale inventories of chemicals if normalization is applied in the assessment. ${ }^{4}$

In both types of applications, it is important that the emission inventories are as complete and representative as possible of the actual emissions. Emission databases are the primary source for building such inventories, although public reports and scientific literature can also provide useful insights (e.g., as defined in Laurent et al. ${ }^{7}$ ). In practice, the completeness of the inventories of chemicals cannot be achieved by only using national emission databases because emission data (1) are typically available for a limited number of pollutants and (2) are associated with large accounting and reporting variations across regions in the world. Addressing point (1) is challenging since it requires estimating the releases of substances, on which no data exists (see ref 7). Emission databases, in fact, typically cover a few dozen, sometimes a few hundred substances, while thousands of chemicals might potentially end up in the environment (e.g., the EINECS list

Received: January 1, 2014

Revised: April 27, 2014

Accepted: April 29, 2014

Published: April 29, 2014 
currently contains ca. 100000 chemicals of potential use on the European market). Mitigating this limitation is not addressed in the present study.

With regard to point (2), extrapolations can be performed to fill in the gaps and to estimate emission inventories in countries or regions where data are not available. The key in this exercise is to find out the appropriate extrapolation parameters or proxies. The appropriateness of a proxy is defined by its availability for the regions that are considered and its ability to match the trends in the emissions of given pollutants. Proxies can be differentiated according to different criteria, for example, the type of emitted pollutant, the source of the emissions, and the type of activities.

Until now, very little was known about the appropriateness of different proxies for building emission inventories. In previous applications from the field of LCA, most works related to the building of inventories of chemicals have used the gross domestic product (GDP) to extrapolate emissions from one or several countries to a full region or to the entire world, although other proxies have also been used for specific substances, for example, a harvested area used as proxy for pesticide application from one country to another. ${ }^{8}$ In this study, together with the GDP (reference year $2010^{\circ}$ ) we test and compare the validity of the extrapolation of toxic emissions based on the emissions of carbon dioxide $\left(\mathrm{CO}_{2}\right.$, reference year $\left.2009^{10}\right)$, and alternatively, based on the emissions of mercury $\left(\mathrm{Hg}\right.$, reference year $\left.2010^{11}\right)$. We aim to address some of these knowledge gaps and to explore different opportunities to build comprehensive inventories from the emission data available in public databases in a selection of countries of the world. The focus of the study is primarily centered on the generation of a European and a global inventory of toxic emissions and the testing of the proxies and assumptions used for the creation of such inventories. These considerations could broadly be applied to extrapolations at a country level. The creation of the European inventory is determined by the greater availability of data for this region.

In the following section, the procedure for the composition of the European and global inventories are detailed, together with the basis for the extrapolation process. The uncertainties related to the process of the collection of national data and their extrapolations to the world are discussed with example substances showing great statistical correlation to a specific proxy. In the remainder of the study, the results are compared and discussed, and recommendations are provided to practitioners and researchers with approaches for building emission inventories of toxic pollutants.

Regional and global inventories of toxic emissions support decision-makers, allowing them to improve environmental regulations and to identify toxic emissions for which control and limits are needed. A possible use for the created inventories is to quantify the impacts associated with the emissions recorded in a certain area. The use of specific sets of characterization factors elaborated in the field of LCA, USEtox, $^{12}$ allows for the calculation of a total impact score for the inventories obtained for the 27 European countries plus Switzerland, Norway, Iceland, and Serbia (EU) and the globe. The process of characterization of the inventory allows us to check the importance of the inclusion or the exclusion of some pollutant emissions (e.g., due to lack of data) and to identify the most contributing substances to the overall impacts. Incidentally, the resulting impact scores can also be regarded as normalization references, which are thus directly applicable to the normalization practice in LCA studies. Three extrapolation proxies are investigated in the present study, namely GDP (reference year $2010^{9}$ ), the emissions of carbon dioxide $\left(\mathrm{CO}_{2}\right.$, reference year $\left.2009^{10}\right)$, and the emissions of mercury $\left(\mathrm{Hg}\right.$, reference year $\left.2010^{11}\right)$.

\section{MATERIALS AND METHODS: BUILDING THE INVENTORY, DATA COLLECTION, AND EXTRAPOLATIONS}

The assessment of the quantity of chemicals emitted at the global scale was based on the development of extrapolation strategies applied to existing chemical inventories at the country scale. First, an inventory of toxic emissions for Europe was developed by enlarging currently available inventories in terms of the number of chemicals and updating the data to 2010, that is, the year in which emissions occurred-see section 2.1. Details on the data sources, necessary extrapolations, limitations, and uncertainties of the emission data are reported. Second, additional chemical inventories were collected from already compiled national registries for the United States, Canada, Japan, and Australia-see section 2.2. These inventories were used to extrapolate global emissions using three different proxies as presented in section 2.3.

2.1. EU Toxic Emissions Inventory. The emission inventory for Europe primarily covers the EU-27 countries plus Switzerland, Norway, Iceland, and Serbia (EU). The inventory covers releases to all emission compartments, that is, air, water, and soil. In Table 1, the substance groups considered in the inventory are detailed, with the relative sources of the data and an estimate of the goodness of the coverage obtained for each group. A detailed table presenting further uncertainties and limitations as well as the added value of the present inventory compared to previous emission inventories is presented in Table S1 of the Supporting Information.

2.1.1. Airborne Emissions. Data on HM and POPs emissions were collected from the EMEP/CEIP Centre ${ }^{13}$ (see Table S2 in the Supporting Information). Only the set of emissions reporting "Officially reported emission data" was used. The set of "Emissions as used in the EMEP models" was excluded because of potential inconsistencies between the two sets of data determined by recalculations and different gapfilling procedures. The completeness of the official registry differs from one country to another and from one sector to another. ${ }^{13}$ Uncertainties are strongly dependent on the aggregation level that was used. Since only the totals for the whole EU region were used, without any further country and sector disaggregation, these uncertainties are believed to be negligible.

The total NMVOC emission data were retrieved from the "Officially reported emission data" reports. ${ }^{13}$ The data were extracted at the country level and 107 activity sectors were distinguished. For each country, the sector-specific total NMVOC emissions were combined with speciation profiles, that is, distributions of the NMVOC in single substances per sector of activity, to derive single NMVOC emissions. Details on the data sources and the methodology for assigning the speciation profiles to the total NMVOC emissions can be found in the publication by Laurent and Hauschild (2014). ${ }^{22}$ The data on industrial emissions of HMs and organics were taken from the EMEP database $\mathrm{e}^{13}$ and established through Regulation (EC) No $166 / 2006$ on releases from industries. The database contains data on the main pollutant releases of about 28000 industrial facilities across the European Union and EFTA 
Table 1. Overview of Substance Groups, Data Sources, and Coverage Estimates

\begin{tabular}{|c|c|c|}
\hline substance groups & data sources & coverage estimate $^{a}$ \\
\hline \multicolumn{3}{|c|}{ Air Emission } \\
\hline HM & CLTAP/EMEP (EMEP 2013) & $* * *$ \\
\hline $\begin{array}{l}\text { organics (non-NMVOC) (e.g., } \\
\text { dioxins, PAH, HCB) }\end{array}$ & CLTAP/EMEP (EMEP 2013) ${ }^{13}$ & $* * *(\mathrm{EMEP})$ \\
\hline \multirow[t]{5}{*}{ NMVOC } & E-PRTR (EEA 2012) $)^{17}$ & $* *(\mathrm{E}-\mathrm{PRTR})$ \\
\hline & total NMVOC per sector from EMEP/CORINAIR (EMEP 2013) & $* * *$ \\
\hline & literature sources (speciation per sectors) & $* * *$ \\
\hline & databases + CORINAIR ${ }^{23,24}$ for sector activity modeling & \\
\hline & Water Emission & \\
\hline \multirow[t]{2}{*}{ industrial releases of $\mathrm{HM}+$ organics } & E-PRTR (EEA 2012) ${ }^{17}$ & $* * *(\mathrm{HM})$ \\
\hline & waterbase $(\text { EEA } 2013)^{15}$ & * (organics) \\
\hline urban WWTP (HM + organics) & waterbase (EEA 2013), ${ }^{15}$ OECD (2013), ${ }^{14}$ EUROSTAT $(2013)^{16}$ & $\begin{array}{l}\text { * (EU covered via extrapolations from } \\
\text { few countries) }\end{array}$ \\
\hline \multicolumn{3}{|c|}{ Soil Emission } \\
\hline industrial releases (HM, POPs) & E-PRTR (E-PRTR 2012) ${ }^{17}$ & $*$ \\
\hline \multirow{3}{*}{$\begin{array}{l}\text { sewage sludge (containing organics } \\
\text { and metals) }\end{array}$} & EEA $(2012)^{17}+$ EUROSTAT $(2013)^{17}$ for usage & \multirow[t]{3}{*}{$* * *(\mathrm{HM})$} \\
\hline & EC $(2010)^{17}$ for HM composition & \\
\hline & Pistocchi et al. (2011) for dioxins ${ }^{17}$ & \\
\hline \multirow[t]{2}{*}{ manure } & FAOSTAT (2013), ${ }^{17}$ Amlinger et al. (2004), ${ }^{20}$ Chambers et al. $(2001)^{21}$ & $* * *$ \\
\hline & Pesticides & \\
\hline \multirow[t]{3}{*}{ active ingredients (AI) breakdown } & $\begin{array}{l}\text { pesticide usage data: FAO }(2012)^{10} \text { and }(\mathrm{F}, \mathrm{H}, \mathrm{I}, \mathrm{O}+\text { chemical classes })+ \\
\text { EUROSTAT }(2013)^{16} \text { for second check }\end{array}$ & \multirow[t]{3}{*}{$* *$} \\
\hline & use of extrapolations for AI differentiations & \\
\hline & EUROSTAT $(2013)^{16}$ for crop harvested areas & \\
\hline
\end{tabular}

${ }^{a}$ The values represent the completeness of the background data in terms of geographical coverage in Europe. The coverage of the emission data is estimated with respect to the countries covered (out of the EU-27) and the substances included (e.g., the number of substances considered) based on expert judgment. The symbols used in the table are as follows: $* * *=$ good coverage; $* *=$ medium coverage; and $*=$ poor coverage. The following acronyms are used in the table: HM = heavy metals; NMVOC = nonmethane volatile organic compounds; WWTP = wastewater treatment plants; POPs = persistent organic pollutants; $\mathrm{PAH}=$ polycyclic aromatic hydrocarbon; and HCB = hexachlorobenzene.

countries. The available data represent the total annual emission releases during normal operations and accidents. The substances identified as not present in the data extracted from $\mathrm{EMEP}^{13}$ but reported in E-PRTR ${ }^{18}$ were added to the inventory (see Table S4 in the Supporting Information).

2.1.2. Water-Borne Emissions. Emissions into water were assessed by considering the industrial emissions of HMs and organics and the emissions coming from wastewater treatment plants. The data available on oil spills were too incomplete to be added.

The data on water-borne emissions of HMs and organics were extracted from the E-PRTR database, ${ }^{18}$ accounting for $90 \%$ of water-borne emissions. With regard to water-borne emissions, the data for 62 substances ( 9 HMs, 53 organics) were retrieved; however, large discrepancies in the country coverage at the EU level occurred as a result of variations in industrial activities from one country to another or incomplete reporting for some countries. Table S5 in the Supporting Information provides an overview of the country coverage per substance.

The Waterbase ${ }^{15}$ database was used to estimate the releases into freshwater of HMs and organics via wastewater, including wastewater releases from industries covered in the E-PRTR. ${ }^{18}$ The risk of double-counting was avoided by a careful analysis of the data. The data for 2009 were used because they were more complete than those for the year 2010 at the time of data collection. The emissions reported in the Waterbase ${ }^{15}$ were aggregated at a country level and regarded as profiles, which were normalized with the population either connected or not to WWTP. These normalized numbers were used for extrapolating to unreported countries.
Data were available mainly for The Netherlands and for a limited set of other countries, for which complete emission profiles could typically not be retrieved (e.g., in case of a population not connected to WWTP). Furthermore, data gaps regarding the apportionment of different wastewater handling facilities were identified for a number of countries. Source types are reported in Tables S6a and S6b of the Supporting Information. A framework was developed to estimate the releases from households and institutional or commercial activities. The framework relies on the assumption that releases can be defined on a per-capita basis, accounting for a differentiation of the countries, and the percentage of population connected to WWTP. The framework is reported in Figure S1 of the Supporting Information and detailed in ref 16. In Table S7 of the Supporting Information, water emissions from all other sources included in the inventory are reported, although their country coverage was limited.

2.1.3. Soil-Borne Emissions. Soil-borne emissions are related mainly to industrial releases, to the direct application on soil of sewage sludge (i.e., as soil amendment after specific treatment) and manure (i.e., as fertilizer on agricultural land), and to pesticide use. For soil-borne industrial emissions, data were extracted from E-PRTR, ${ }^{18}$ which reports emissions for 23 substances ( $8 \mathrm{HMs}, 15$ organics). Large limitations in the country coverage were observed due to variations in industrial activities from one country to another or incomplete reporting for some countries (Table S8 of the Supporting Information).

Sewage sludge was included in the inventory as a substantial source of releases of organics and HMs. The data on the use of sewage sludge applied to agricultural land was retrieved from the OECD. ${ }^{14}$ Extrapolations of data from one country to 
another were performed by coupling the emission data with average country-specific concentrations of $\mathrm{HMs}(\mathrm{Zn}, \mathrm{Cu}, \mathrm{Pb}$, $\mathrm{Ni}, \mathrm{Cr}, \mathrm{Hg}, \mathrm{Cd}$ ) and dioxins. ${ }^{17}$

For the emissions of HMs present in manure and slurry, country-specific concentrations were coupled with the respective national use of manure and slurries. The use of manure can be a substantial source of HMs in particular because of the mineral additives present in the feedstock for animals (e.g., pig manure and slurry is typically associated with high levels of zinc and copper ${ }^{17}$ ). The data on animal livestock, obtained from FAOSTAT, ${ }^{17}$ was matched to the metals associated with the production of manure per type of living animal (e.g., mule, goat, or sheep) per year, as reported by Delahaye et al. ${ }^{25}$ The soil manure figures are reported as tons of nitrogen content for nine different animal types (see Table S9 in the Supporting Information). The content of nitrogen was evaluated per weight of dry matter. The data for solid manure retrieved from Chambers et al. ${ }^{21}$ were used for that purpose and were differentiated according to the nine types of livestock considered. HM concentrations were extracted from Amlinger et al. $^{20}$ When no further specification was available, averages were assumed to be representative for the other countries.

For the inventory of pesticides, emission data were disaggregated on a single-substance basis, that is, broken down into AI. This information is rarely available because of confidentiality issues and commercial interests from the chemical-producing companies. The main data source used in the present study is a report by the EU Commission ${ }^{26}$ that contains detailed information on pesticide usage disaggregated into EU countries (minus Bulgaria and Romania) and major types of crops (e.g., cereals, maize).

From the report, the top-five amounts of active ingredients used and the top-five chemical classes with their associated average dosage (e.g., in $\mathrm{kg} \mathrm{AI} / \mathrm{ha}$ ) were collected for each country and for each type of crop (year 2003). The top-five chemical classes with their associated average dosage for each type of crop and for each of the three major classes of pesticides, namely fungicides, insecticides, and herbicides were additionally retrieved (year assumed to be 2003).

The outcome after the gap-filling procedure was the applied quantity of five active ingredients in 2003 for each country and crop system. With knowledge of the harvested areas per type of crops in 2003 and 2010, an extrapolation was performed using the same AI composition and dosage in 2010 as in 2003. Several gaps occurred in the data set because of confidentiality issues related to specific active ingredients that were flagged as "confidential" in the report with no further data provided. A gap-filling procedure was therefore developed to derive a pesticide inventory as complete and consistent as possible-see the documentation in the Supporting Information.

2.2. Regional Inventories for the United States, Canada, Australia, and Japan. Only a restricted number of countries outside the EU provide and organize data on toxic emissions. ${ }^{27,28}$ Public efforts of data collection and reporting vary in their details across different countries. Only a selected number of toxic substances are monitored in most countries. While it was possible to operate an ad hoc compilation of the inventory combining data from a number of European agencies at the EU level (see section 2.1), it was possible to use only the available combined information from national registries for a few other countries in the world for the chosen reference year. Of these, the publicly available national pollutant release and transfer registers (PRTRs) of the United States, ${ }^{29}$ Canada, ${ }^{30}$
Japan, $^{31}$ and Australia ${ }^{32}$ provided a coherent data set to be used. Data were collected for the compartments of air, freshwater, industrial soil, and natural soil (including landfills).

In general, the US-EPA provided the biggest coverage in terms of number of substances, with detailed information on emission and disposal of over 650 chemicals from more than 20 000 U.S. facilities. ${ }^{29}$ The transfer registry collects data on chemical emissions directly from selected sectors (e.g., manufacturing, mining, power generation) with a certain production throughput of enlisted chemicals (including pesticides). Emissions are registered per compartment (i.e., air, water, soil, landfill) on-site and off-site. Information on recycling and recovery is also available.

Information on the emission of 346 substances from 8096 facilities was obtained from the Canadian NPRI, ${ }^{30}$ with details on emissions, disposal, and recycling. The sectors with the largest reported emissions were oil and gas extraction; electricity generation, transmission, and distribution; and primary metal smelting.

The Australian registry was used to inventory emission estimates for 93 toxic substances with details on the source and location of these emissions. The selection conducted by the registry on the chemical to be reported was conducted based on a risk score, defined as a function of the environment hazard and the human health, and the exposure to a certain substance.

In Japan, a total of 354 substances reported by the PRTR registry ${ }^{31}$ - with data directly recorded from relevant sectors of the economy-were included in the inventory. For the Japanese database, it was possible to integrate into the calculations the percentage of facilities (e.g., a specific chemical factory in the Honshu region) that reported emissions for each substance.

Each of the extra-EU data sets was then analyzed and the emissions were recorded by an automated search using the unique numerical identifiers assigned by the Chemical Abstracts Service (CAS). When no CAS number was available, each substance was searched by name in each different database and was added consequently. In all cases where no match was found (e.g., misspelled name or different acronym), substances were searched by their names and acronyms in the different registers. For some substances, a greater coverage was available in registries other than the EU registry. In this case, the relative name and specifications were added to the original list, and the relative emissions were recorded.

We refered to the original sources for the details on the composition of the inventories and the assumptions that were made in the process. In the Supporting Information, the final inventories used are reported and are available for consultation.

2.3. Extrapolation of the Regional Inventories to the Globe. The limited availability of data required us to use estimation factors or proxies, as recommended by Sleeswijk et al., ${ }^{8}$ in order to populate the inventory of the world emissions. In the EU inventory, extrapolations were used to fill gaps due to limited country coverage, thanks to the information reported by the consulted registries. Extrapolation strategies were also applied for the extrapolation from the EU, United States, Canada, Japan, and Australia to the world. GDP, $\mathrm{CO}_{2}$ emissions, and $\mathrm{Hg}$ emissions allowed for the filling of data gaps and for the quantification of the total emissions.

The use of a GDP-based strategy can be supported by the fact that emissions of a pollutant may be associated with economic growth and economic activities of different regions. Empirical evidence has been available since the early nineties 
and concepts such as the Environmental Kuznets curve (see Stern $^{33}$ ) may support the use of the GDP as a proxy for filling data gaps and for the extrapolation of local and regional data to the entire world, since the measure is related to the magnitude of industrial production and, thus, to the relative releases of toxins. In the context of normalization in LCA, GDP has proven to have a good correlation with emissions of certain toxic substances, but a correlation not as strong for, for example, pesticides (see ref 8). As an alternative, a $\mathrm{CO}_{2}$ emission-based strategy is proposed, which may be more suitable for certain sectors and substances (Davis and Caldeira ${ }^{34,35}$ ). Additionally, the global effort to quantify and contain anthropogenic emissions of $\mathrm{Hg}^{11}$ provided a solid data source to test $\mathrm{Hg}$ emissions as an extrapolation basis. $\mathrm{Hg}$ emissions were tested as a proxy related to activities in certain countries for emissions that are difficult to catch using $\mathrm{CO}_{2}$ emissions or the GDP (e.g., small-scale gold mining, treatment of electronic waste $\left.{ }^{11}\right)$.

The extrapolations were based on the formula

$$
X_{i ; m}=\frac{\sum_{j} X_{i, j} \times R_{j ; m}}{\sum_{j} R_{j ; m}}
$$

where $X_{i, j}$ is the amount of substance $i$ emitted to the region $j$, $R_{j ; m}$ is the extrapolation factor for the region $j$ with the extrapolation principle $m$ (i.e., $\mathrm{CO}_{2}, \mathrm{GDP}, \mathrm{Hg}$ ), and $X_{i ; m}$ is the amount of substance $i$ emitted to the world, estimated with the extrapolation principle $m$.

At the EU level, the extra details on the country where the emissions took place allowed us to proceed with a further extrapolation of the data. For certain substances, large discrepancies, in fact, in the country coverage occurred because of variations in industrial activities or the incomplete reporting of emissions. To fill in the data gaps in the inventory, the GDP was used to interpolate in space (i.e., across countries) the available emission data from E-PRTR ${ }^{18}$ in order to obtain more representative estimates of the emissions of substances to the level of the EU region as a whole. For those emissions for which data were obtained from European statistical data (i.e., from EEA, EUROSTAT, EU, EMEP), the countries reporting a certain emission were used as a proxy for the calculation of the European region as a whole. Inventories from the regional registries other than the EU were not subject to extrapolation. Extrapolations to the world were then conducted based on the formula provided in the previous section (section 2.3). Inventories were compiled for the two macroregions, the EU and the world. For the world, three different global inventories were defined using the three different extrapolators (i.e., world extrapolated with $\mathrm{CO}_{2}$ emissions, world extrapolated with the GDP, world extrapolated with $\mathrm{Hg}$ emissions). Alternative compositions of the world inventory are reported in section 3 of the Supporting Information.

\section{RESULTS}

3.1. Inventories. For the composition of the inventories of toxic emissions, it was necessary to deal with data from various sources, all with a different coverage across substance groups and across countries. Information on the emissions of chemicals was not equal for all of the countries that were used for the creation of the global inventory; thus, the highest level of uncertainty in the process of composing the global inventory regards the extrapolation to the world of data that refers to a limited region within a specific economic system.
In the process of the creation of the global inventory, it is unrealistically assumed that all emission data have been collected according to a common standard and to common selection and validation criteria. However, the sheer differences in the data collection processes across countries bias the final results. Some national registries are not reporting monitored or measured data, but rather the result of a previous process of data extrapolation and the result of a series of assumptions. The variability of substance coverage determines unavoidable overand under-estimations of substances when data is extrapolated from one region to the entire world. It is in this sense significant that the final global quantity of pesticides is mostly driven by data that was, with few exceptions, elaborated at the EU level, thus increasing the level of uncertainty of the final result. Other pesticides were used, or not used, in other regions. Moreover, as reported in section 2.1, the limited possibility of obtaining accurate data on active ingredients used in the pesticides complicated the modeling process because of the lack of information in EU case, also. Other substance groups may suffer from the same bias, which needs to be further analyzed.

3.2. Goodness of Fit of the Used Proxies. The extrapolation proxies used in this paper were selected either because their correlations with emissions had been already used and proven by other studies (i.e., the GDP measure and $\mathrm{CO}_{2}$ emission) or because of the presence of an international coordinated effort to produce a rigorous and complete database of emissions for a wide set of countries of the world (i.e., the case of $\mathrm{Hg}$ ). Other extrapolation parameters may be tested in the future and used in specific cases (e.g., cultivated crop area per country as a proxy for the use of pesticides).

To investigate the assumption behind the extrapolation work, data available for 234 countries relative to the estimators were crossed to investigate the direct correlation among the factors used in this paper. A high overall correlation was found at a global level between the GDP and $\mathrm{CO}_{2}$ (Pearson coefficient, 0.8 ), suggesting that the two predictors (both strongly correlated to energy production) may both be used interchangeably in the extrapolation of the data. A significantly lower correlation was found between emissions of $\mathrm{Hg}$ for the countries analyzed and both the GDP and $\mathrm{CO}_{2}$ (Pearson coefficient, 0.4 ), suggesting that both predictors may not be the best possible estimator when used for the extrapolation of $\mathrm{Hg}$ emissions, or, assuming a correlation among heavy metals, they would not be the best predictors also for other metals. The comparison of residual errors highlighted the cases of over- or under-estimation of emissions of $\mathrm{Hg}$, using the GDP or $\mathrm{CO}_{2}$ as a predictor. A country-by-country analysis of the goodness of fit is shown in Figure 1 below.

The analysis of the prediction suggests that the regions used in this paper as extrapolation bases were precisely estimated or slightly overestimated (see, e.g., EU and Australia). The highest level of underestimation affects countries with a lower GDP (e.g., central African countries and a number of South American countries). The pattern seems to correspond to the hypothesis that for countries in which the extraction of resources (e.g., gold $^{11}$ ) that are related to mercury release is not conducted according to controlled standards, GDP and $\mathrm{CO}_{2}$ (see Figure $\mathrm{S} 4$ in the Supporting Information) do not function as the best possible predictors. On the other hand, no strong overestimation of $\mathrm{Hg}$ was detected in any country. The data suggests that care should be taken when dealing with extrapolation strategies for certain substances. The use of GDP-based and $\mathrm{CO}_{2}$-based strategies can be supported by the 


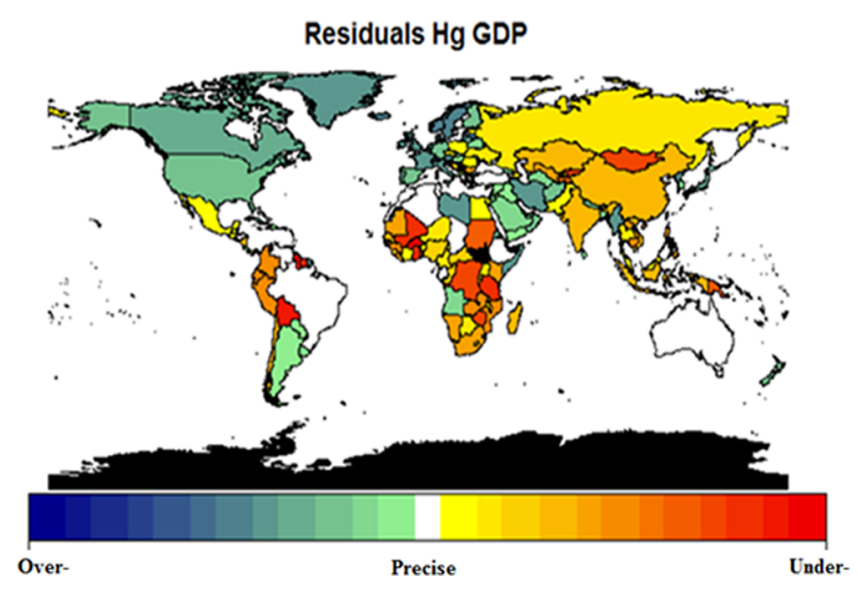

Figure 1. A map of residuals displaying the goodness of prediction of $\mathrm{Hg}$ emissions (UNEP, 2013) per country when using the GDP measure. The results shown are based on the residual difference between a model predicting an $\mathrm{Hg}$ emission in a single country using the GDP measure and the real value of $\mathrm{Hg}$ in that country. Following the color scale, the data in red refers to countries that were underestimated, the data in blue refers to countries that were overestimated, and the data in white refers to countries for which the prediction provides a good fit. Intermediate coloring corresponds to a variation in fitness (in the range \pm 2.3 ). No data was available for the countries shaded in black.

coupling of many pollutant emissions with the economic activities of a region; however, the $\mathrm{Hg}$-based extrapolation strategy is recommended for use for those countries with a low GDP and $\mathrm{CO}_{2}$, but in which some activities poorly correlated with the GDP and $\mathrm{CO}_{2}$ (e.g., mining) are very relevant and otherwise underestimated.

3.3. Uncertainty. To further analyze the strength of prediction obtained using the three estimators, a subset of representative substances, including the top-contributors to the EU and world impact scores, was selected based on the availability of sufficient recorded data in the EU and the rest of the countries accounted for in the composition of the global inventory. To guide future extrapolations and analyses, the statistical check was conducted also for a sample of other substances that did not show up as top-contributors. The data was analyzed distinguishing between emission to the air, water, and soil as accounted for by the national registries. Data from the E-PRTR registry ${ }^{18}$ for the year 2010 was extracted for the EU and combined with the other relevant country data. Emissions were reported for 34 countries of the world. Each of the three predictors used in the extrapolations were matched to the reported data, and an analysis of the linear correlation was conducted. A logarithmic transformation was used before analyzing the data. Detailed results are presented for each case in sections S3.1 and S3.2 of the Supporting Information. In Figure 2, the strength of the predictors was tested for the emission of zinc to the air as reported by refs 12,23 , and 29-32. The strongest $R$-squared value (0.7) was obtained when $\mathrm{CO}_{2}$ was used as a predictor. The results of the statistical analysis for all of the other cases studied are reported in Table 2 below and in the Supporting Information.

In general, it was not possible to define a better predictor for all substances or groups of substances. Differences were found at the substance level as well as at the compartment level. In particular, for the emissions to soil, it was not possible to obtain strong correlations due to the limited availability of data. Further estimators need to be tested in future work to verify case-by-case and for the established top contributors (i.e., HMs and selected pesticides) for which the estimators are best suited for the composition of a global inventory.

\section{DISCUSSION}

4.1. Impact Assessment of the EU and Global Inventories. The USEtox-based toxic impact categories, ${ }^{12}$ that is, freshwater ecotoxicity and human toxicity, were used to characterize the inventories. The impacts (or normalization references in the context of LCA) were calculated by the multiplication of each reference intervention within each geographical system with the compartment-specific characterization factors. Tables $S 10$ and $S 11$ in the Supporting Information provide the results after the characterization of the inventories (or normalization references in LCA),
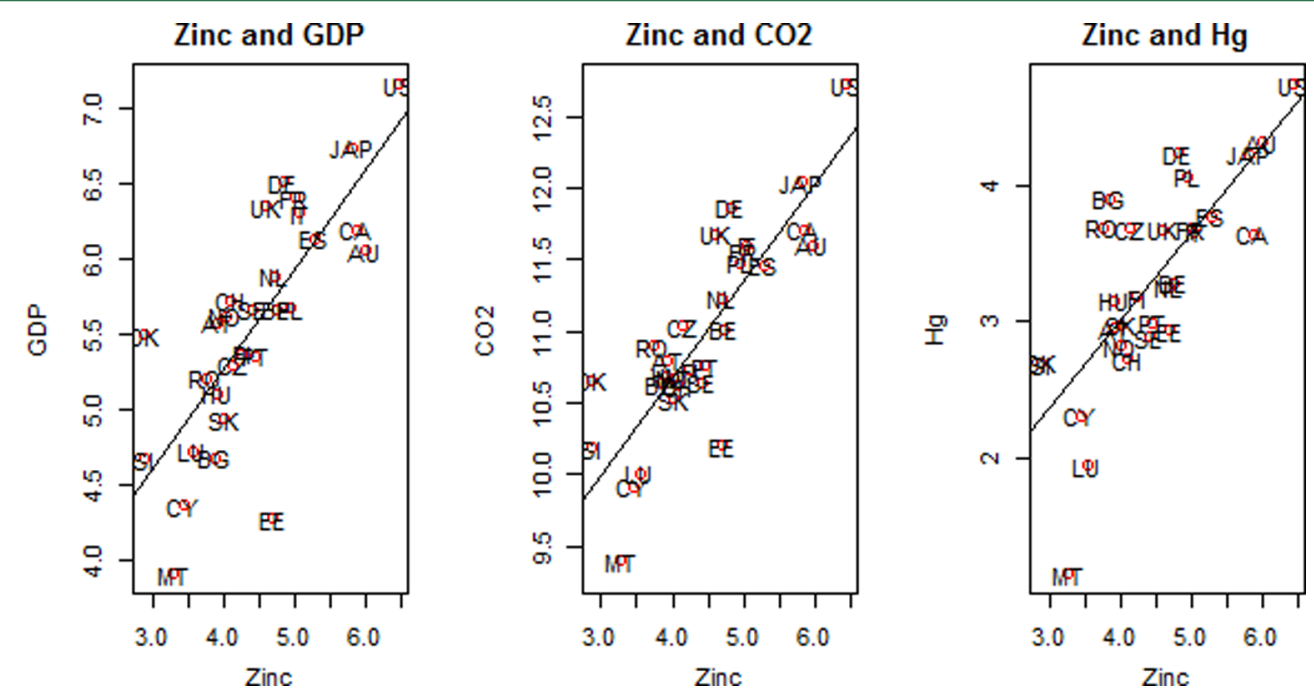

Figure 2. Investigation of the strength of the linear relationship between zinc to the air (EMEP, 2013; and national emission registries for the United States, Canada, Japan, and Australia) and the GDP, $\mathrm{CO}_{2}$, and $\mathrm{Hg}\left(R\right.$-squared $=0.5727, p$-value $=1.227 \mathrm{e}^{-06} ; R$-squared $=0.7007, p$-value $=9.227 \mathrm{e}^{-09}$; $R$-squared $=0.5584, p$-value $=1.938 \mathrm{e}^{-06}$, respectively). The scale is logarithmic, the quantities are in kilograms, and the countries are represented by ISO 3166-1 alpha- 2 country codes. 
Table 2. Investigation of the Strength of the Correlation between the Prediction of a Linear Model Relating the Emitted Amount of a Substance to Air, Water, and Soil to the Extrapolation Factors

\begin{tabular}{|c|c|c|c|c|c|c|c|c|c|}
\hline \multirow[b]{3}{*}{ emission } & \multicolumn{9}{|c|}{ adjusted $R$-squared value } \\
\hline & \multicolumn{3}{|c|}{ GDP } & \multicolumn{3}{|c|}{$\mathrm{CO}_{2}$} & \multicolumn{3}{|c|}{$\mathrm{Hg}$} \\
\hline & air & water & soil & air & water & soil & air & water & soil \\
\hline zinc & 0.57 & 0.59 & 0.46 & 0.7 & 0.7 & 0.48 & 0.56 & 0.7 & 0.01 \\
\hline mercury & 0.48 & 0.42 & 0.63 & 0.69 & 0.51 & 0.57 & 0.82 & 0.43 & 0.26 \\
\hline lead & 0.15 & 0.45 & 0.18 & 0.37 & 0.59 & 0.21 & 0.43 & 0.61 & 0.05 \\
\hline cadmium & 0.37 & 0.36 & 0.36 & 0.58 & 0.48 & 0.46 & 0.57 & 0.63 & 0.01 \\
\hline chromium & 0.27 & 0.29 & 0.15 & 0.49 & 0.46 & 0.25 & 0.69 & 0.55 & 0.04 \\
\hline arsenic & 0.29 & 0.41 & 0.32 & 0.48 & 0.51 & 0.37 & 0.52 & 0.48 & 0.1 \\
\hline copper & 0.49 & 0.48 & 0.36 & 0.69 & 0.63 & 0.45 & 0.68 & 0.65 & 0.19 \\
\hline benzo(a)pyrene & 0.17 & & & 0.12 & & & 0.27 & & \\
\hline NMVOC & 0.55 & & & 0.73 & & & 0.54 & & \\
\hline 1,2- dichloroethane & 0.04 & 0.26 & & 0.05 & 0.01 & & 0.05 & 0.3 & \\
\hline polychlorinated biphenyl & 0.23 & & 0.23 & 0.29 & & 0.3 & 0.21 & & 0.21 \\
\hline
\end{tabular}

considering the impacts on human toxicity and freshwater ecotoxicity in the EU geographic system and for the world system. As in Sleeswijk et al., 8 an emission total consists of the summed emissions of a substance to a specific compartment in one of the geographic systems. The results are reported per year using the notation suggested by Heijungs. ${ }^{36}$

The characterization of the inventory by means of an impact system such as USEtox allows for testing of the inventory and identifying the effects of the extrapolations on the outcome of the characterization and the calculation of the impacts. As a result, under all of the extrapolations the incompleteness of the data in regions other than the EU is likely to be the cause of a disproportional emission attributed to the EU compared to the rest of the world. The composition of the economic systems in the extrapolation region (i.e., the EU plus other available national registries) influences the final result. The extrapolation based on the $\mathrm{CO}_{2}$ emissions attributed one-third of the global emissions to the EU region (with the EU accounting for a total of $36 \%$ of the world $\mathrm{CO}_{2}$ emissions). The GDP-based extrapolation provided a weight of the EU compared to the world emissions in the range of $50 \%$ for human toxicity (cancer, noncancer, and total), and $37 \%$ for ecotoxicity, with a global GDP of the region accounting for about $27 \%$ of the world GDP. . A limited contribution of the EU to the world was obtained in the case of the Hg-emissions-based extrapolation because of the limited share of mercury emissions that the EU accounts for compared to the rest of the world (i.e., 11\%). The extrapolation of $\mathrm{Hg}$ emissions gave also the highest total impact for the world; an order of magnitude higher than the GDP and $\mathrm{CO}_{2}$ for the impact of human toxicity and one order of magnitude higher than the GDP for the total impact of ecotoxicity. As reported by Sleeswijk et al., ${ }^{8}$ the reliability of the estimation factors depends on the strength of the correlation between the emissions and the predictor used to extrapolate them from a limited geographic extent to the entire globe (or potentially from a bigger macroregion to a country level).

A list of the top-contributing substances was extracted from the data (see Table S12 in the Supporting Information). The comparison of the three strategies did not highlight the differences in the top-substances that contributed to the totals, while the share of the contribution was slightly different among them. This is a logical result from the extrapolation strategy described in section 3. Logically, the ratios of GDP, $\mathrm{CO}_{2}$ emissions, and $\mathrm{Hg}$ emissions in the extrapolation regions and in the world are identical for all substances; therefore, the emission of a substance is transferred from the extrapolation region to the world based on all predictors geometrically. Slight differences arise when a particular substance has a different initial geographical coverage than the other substances. The nearly perfect matching of the top contributors for the three predictors (see Table S12 of the Supporting Information) also reflects the fact that most emissions are driven by energy processes, which are likely to be the best covered processes across all databases. Other processes may actually contribute to toxic emissions without being related to energy processes, in which case the extrapolations based on $\mathrm{Hg}$ emissions would lead to decoupled results from the ones obtained with $\mathrm{CO}_{2}$ emissions and the GDP. However, such sectors may not be well covered in national or regional registries. The type of activities that are related to the emissions of $\mathrm{Hg}$ may be more relevant for other economic systems than for the ones used for the composition of the global inventory. Such sectors are better covered in life cycle (LC) inventories, in which a number of chemical releases are still missing. Similarly, it is possible to observe a decoupling between the climate footprint and toxic impacts when using LC inventories (see Laurent et al. ${ }^{37}$ ), which are in most cases deemed more complete than the national or regional databases.

4.2. Outlook and Implications. This study provides a detailed analysis of the process of the compilation of regional and global inventories of toxic emissions and may be of interest also for the reverse process of extrapolations from a bigger to a smaller scale. During the process of building the emission inventory, the modeler has to deal with a limited international accounting of emission data and with different standards of collection (e.g., substance groups reported in one region only). Extrapolations, thus, were required to fill data gaps. Certain substances are likely to be underestimated by the process; some others are likely to be overestimated. Particularly relevant are the cases of substances that are not necessarily an integral part of the economic system of developed countries. In these cases, the extrapolation process is possibly ignoring activities that are not recorded in those countries but would be relevant on the global scale (e.g., processing of electronic waste in the developing world). Of similar importance is the case of substances that have already been banned in certain countries, but still used in others, and thus, would not appear in the result of the extrapolation process.

The three estimators used for the extrapolations, while convenient for the population of the emission database, were 
not in all cases representative of the global reality that they try to picture. The analysis of the direct correlation between the estimators for 234 countries of the world showed that theoretically the GDP and $\mathrm{CO}_{2}$ could be used alternatively as estimators, while neither the GDP nor $\mathrm{CO}_{2}$ would be suitable to predict $\mathrm{Hg}$ emissions. Such a consideration could be extended to other metals and substances that are emitted in combination with $\mathrm{Hg}$.

We showed, for a sample of relevant substances, that the correlation between each estimator and a substance greatly varies across substances and also across compartments for the same substance. The theoretical strong correlation between the GDP and $\mathrm{CO}_{2}$ in the country-by-country analysis was not reproduced by this analysis. The statistical analysis highlighted that it is not possible to select a single best predictor on the basis of the correlation between the reported data and the value of the predictor. A case-by-case analysis may help in the future to develop more stable predictors for a cluster of substances or for a cluster of countries with a similar economic structure. A more in-depth analysis should be conducted to evaluate if ad hoc extrapolation factors (e.g., crop production area assumed to be related to pesticide use) are needed for a better coverage of emissions.

Future work should be oriented to quantifying more accurate emission inventories for the top-contributors that arise from different characterization methods. Some other approaches such as bottom-up data extrapolation using, for example, technology and energy correction factors or the use of environmentally extended input-output tables (see in Tukker et al. $^{38}$ ), where available, could be helpful for extrapolations. Future work should explore where better correlations might be found. The EU and global inventories compiled in this study may be used as a basis for such an analysis. The comparison of the impacts and the top-contributors should then be used as guidance for future data collection efforts. Once enough data has been gathered on a shortlist of top-contributors, the analysis can move to the remaining $\sim 5-10 \%$ contributors in determining the total impact. This approach would likely increase the possibility of having valuable results in a short-term perspective, obviating the slow process of gathering of data by national and regional authorities, and lowering the risk of incurring one of the potential biases of the process.

\section{ASSOCIATED CONTENT}

\section{(S) Supporting Information}

Inventory data and the template used for the characterization of the inventory. This material is available free of charge via the Internet at http://pubs.acs.org.

\section{AUTHOR INFORMATION}

\section{Corresponding Author}

*E-mail: cucurachi@cml.leidenuniv.nl.

\section{Notes}

The authors declare no competing financial interest.

\section{ACKNOWLEDGMENTS}

The present research was funded by the European Commission under the seventh Framework Programme on Environment; ENV.2009.3.3.2.1: LC-IMPACT-Improved Life Cycle Impact Assessment methods (LCIA) for better sustainability assessment of technologies, Grant Agreement Number 243827.

\section{REFERENCES}

(1) Life cycle indicators framework: development of life cycle based macro-level monitoring indicators for resources, products and waste for the EU-27 (a); European Commission, Joint Research Centre, Institute for Environment and Sustainability: Ispra, Italy, 2012.

(2) Life cycle indicators framework: development of life cycle based macro-level monitoring indicators for resources, products and waste for the EU-27 (b); European Commission, Joint Research Centre, Institute for Environment and Sustainability: Ispra, Italy, 2012.

(3) Life cycle indicators framework: development of life cycle based macro-level monitoring indicators for resources, products and waste for the EU-27 (c); European Commission, Joint Research Centre, Institute for Environment and Sustainability: Ispra, Italy, 2012.

(4) ISO 14040:2006 environmental management-life cycle assessmentprinciples and framework; International Standards Organization: Geneva, Switzerland, 2006.

(5) Guinée, J. B.; Gorrée, M.; Heijungs, R.; Huppes, G.; Kleijn, R.; De Koning, A. Handbook on life cycle assessment. Operational guide to the ISO standards; Kluwer Academic Publishers: Dordrecht, The Netherlands, 2002; 1-708.

(6) Sala, S.; Goralczyk, M. Chemical footprint: A methodological framework for bridging life cycle assessment and planetary boundaries for chemical pollution. Integr. Environ. Assess. Manage. 2013, 9 (4), $623-632$.

(7) Laurent, A.; Olsen, S. I.; Hauschild, M. Z. Normalization in EDIP97 and EDIP2003: Updated European inventory for 2004 and guidance towards a consistent use in practice. Int. J. Life Cycle Assess. 2011, 16 (5), 401-409.

(8) Sleeswijk, A. W.; Huijbregts, M. A. J.; Van Oers, L. F. C. M.; Guinée, J. B.; Struijs, J. Normalisation in product life cycle assessment: An LCA of the global and European economic systems in the year 2000. Sci. Total Environ. 2008, 390 (1), 227-240.

(9) World development indicators; World Bank: Washington D.C., 2010.http://data.worldbank.org/data-catalog/world-developmentindicators/wdi-2010.

(10) FAOSTAT. Statistical data; Food and Agriculture Organization of the United Nations (FAO): Rome, Italy. http://faostat3.fao.org/ home/index.html (accessed April 2013).

(11) UNEP. Global mercury assessment. Sources, emissions, releases, and environmental transport; UNEP Chemicals Branch: Geneva, Switzerland, 2013. http://www.unep.org/PDF/PressReleases/ GlobalMercuryAssessment2013.pdf.

(12) Rosenbaum, R. K.; Bachmann, T. M.; Gold, L. S.; Huijbregts, M. A. J.; Jolliet, O.; Juraske, R.; Koehler, A.; Larsen, H. F.; MacLeod, M.; Margni, M.; McKone, T. E.; Payet, J.; Schuhmacher, M.; Van de Meent, D.; Hauschild, M. Z. USEtox-the UNEP-SETAC toxicity model: Recommended characterization factors for human toxicity and freshwater ecotoxicity in life cycle impact assessment. Int. J. Life Cycle Assess. 2008, 13, 532-546.

(13) EMEP. Country- and sector-specific pollutant emission data; Centre on Emission Inventories and Projections (CEIP). http://www.ceip.at/. Link to database: http://webdab1.umweltbundesamt.at/scaled_ country_year.html?cgiproxy_skip=1 (accessed April 2013).

(14) OECD. StatExtracts - databases providing statistics on wastewater treatment. http://stats.oecd.org/Index.aspx?QueryId=28857\# (accessed June 2013).

(15) EEA. Waterbase for rivers. http://www.eea.europa.eu/data-andmaps/data/waterbase-rivers-8 (accessed February 2013).

(16) EUROSTAT Eurostat statistics database. http://ec.europa.eu/ eurostat (accessed April 2013).

(17) European Commission. Environmental, economic, and social impacts of the use of sewage sludge on land. Final report-part III: Project interim reports; Milieu Ltd, WRc, RPA: Brussels, Belgium, 2008.

(18) E-PRTR. The European pollutant release and transfer register (EPRTR). http://prtr.ec.europa.eu/ (accessed June 2013).

(19) Pistocchi A.; Alamo C.; Castro-Jiménez J.; Katsogiannis A.; Pontes S.; Umlauf G.; Vizcaino P. A compilation of Europe-wide databases from published measurements of pcbs, dioxins, and furans; European Union: Luxembourg, 2010. http://publications.jrc.ec. 
europa.eu/repository/bitstream/111111111/22703/1/lb-na-24266en-c.pdf.

(20) Amlinger F., Pollak M.; Favoino E. Heavy metals and organics compounds from wastes used as organic fertilisers. Final report. REF.NR: TEND/AML/2001/07/20; EU Commission: Perchtoldsdorf, Austria, 2004. http://ec.europa.eu/environment/waste/compost/pdf/hm finalreport.pdf.

(21) Chambers B.; Nicholson N.; Smith K.; Pain B.; Cumby T.; Scotford I. Managing livestock manures-booklet 1: Making better use of livestock manures on arable land [Online]; 2 nd ed.; ADAS Gleadthorpe Research Centre: Nottinghamshire, England, 2001. http://archive. defra.gov.uk/foodfarm/landmanage/land-soil/nutrient/documents/ manure/livemanure1.pdf (accessed February 25, 2013).

(22) Laurent, A.; Hauschild, M. Z. Impacts of NMVOC emissions on human health in European countries for 2000-2010: Use of sectorspecific substance profiles. Atmos. Environ. 2014, 85, 247-255, http:// dx.doi.org/10.1016/j.atmosenv.2013.11.060.

(23) CORINAIR. 2007. http://reports.eea.europa.eu/ EMEPCORINAIR5/en/B1090vs2.pdf (accessed April 2013).

(24) CORINAIR. Emission inventory guidebook. Technical report No. 9; European Environmental Agency: Copenhagen, Denmark, 2009. http://reports.eea.eu.int/EMEPCORINAIR4/en.

(25) Delahaye, R., Fong, P. K. N., Van Eerdt, M. M., Van der Hoek, K. W., Olsthoorn, C. S. M. Emissie van zeven zware metalen naar landbouwgrond (Emission of seven heavy metals to the agricultural soil (in Dutch). Centraal Bureau voor de Statistiek (CBS). Voorburg/ Heerlen: The Netherlands, 2003; 33 http://www.cbs.nl/NR/ rdonlyres/837282FD-9AC2-4529-AB2C-340444892528/0/ zwaremetaleneindrapport.pdf.

(26) The use of plant protection products in the European Union. Data, 1992-2003. epp.eurostat.ec.europa.eu (accessed March 2013).

(27) Cucurachi S., Hejiungs R., Laurent A., Sala S. Normalisation factors for ecotoxicity and human toxicity. Deliverable 2.4 of LC-impact project, 2013. http://www.lc-impact.eu (accessed December 2013).

(28) Pollutant release and transfer registers of the world. http://www. prtr.net/en/links/ (accessed March 2013).

(29) Toxics release inventory (TRI) program. TRI explorer. United States Environmental Protection Agency (US-EPA): Washington DC, USA. http://www.epa.gov/triexplorer/ (accessed March 2013).

(30) Environment Canada National Pollutant Release Inventory (NPRI). http://www.ec.gc.ca/inrp-npri/ (accessed April 2013).

(31) Chemical Management Field; National Institute of Technology and Evaluation (NITE): Japan, http://www.safe.nite.go.jp/english/ index.html (accessed March 2013).

(32) Australian National Pollutant Inventory. http://www.npi.gov. au/ (accessed March 2013).

(33) Stern, D. I. The rise and fall of the environmental Kuznets curve. World Dev. 2004, 32 (8), 1419-1439.

(34) Davis, S. J.; Caldeira, K. Consumption-based accounting of $\mathrm{CO}_{2}$ emissions. P. Natl. Acad. Sci. 2010, 107 (12), 5687-5692.

(35) Davis, S. J.; Caldeira, K.; Matthews, H. D. Future $\mathrm{CO}_{2}$ emissions and climate change from existing energy infrastructure. Science 2010, 329 (5997), 1330-1333.

(36) Heijungs, R. On the use of units in LCA. Int. J. Life Cycle Assess. 2005, 10 (3), 173-176.

(37) Laurent, A.; Olsen, S. I.; Hauschild, M. Z. (2012) Limitation of carbon footprint as indicator of environmental sustainability. Environ. Sci. Technol. 2012, 46, 4100-4108.

(38) Tukker, A.; Poliakov, E.; Heijungs, R.; Hawkins, T.; Neuwahl, F.; Rueda-Cantuche, J. M.; Bouwmeester, M. Towards a global multiregional environmentally extended input-output database. Ecol. Econ. 2009, 68 (7), 1928-1937. 